\title{
Modeling eBook acceptance: a study on mathematics teachers
}

\begin{abstract}
The integration and effectiveness of eBook utilization in Mathematics teaching and learning greatly relied upon the teachers, hence the need to understand their perceptions and beliefs. The eBook, an individual laptop completed with digitized textbook sofwares, were provided for each students in line with the concept of 1 student:1 laptop. This study focuses on predicting a model on the acceptance of the eBook among Mathematics teachers. Data was collected from 304 mathematics teachers in selected schools using a survey questionnaire. The selection were based on the proportionate stratified sampling. Structural Equation Modeling (SEM) were employed where the model was tested and evaluated and was found to have a good fit. The variance explained for the teachers' attitude towards eBook is approximately $69.1 \%$ where perceived usefulness appeared to be a stronger determinant compared to perceived ease of use. This study concluded that the attitude of mathematics teachers towards eBook depends largely on the perception of how useful the eBook is on improving their teaching performance, implying that teachers should be kept updated with the latest mathematical application and sofwares to use with the eBook to ensure positive attitude towards using it in class.
\end{abstract}

Keyword: Attitude towards eBook; eBook; Mathematics teachers; Perceived ease of use; Perceived usefulness 